\title{
Erratum
}

Benjamin Schäfer*

\section{Erratum to: The Impact of the Crisis and Unconventional Monetary Policy on European Inflation Dynamics}

https://doi.org/10.1515/roe-2018-2000

Erratum to: Benjamin Schäfer. August 2018. The Impact of the Crisis and Unconventional Monetary Policy on European Inflation Dynamics. Review of Economics. Volume 69, Issue 2, pages 87-110. (https://doi.org/10.1515/ roe-2018-0016):

The formula in Appendix B (on page 108), was mistakenly printed without symbols of the partial derivatives.

For the reader's convenience, the corrected formula appears below.

$$
\begin{aligned}
\frac{\partial Y_{t}}{\partial N_{t}} & =(1-\alpha) A_{t} K_{t}^{\alpha} N_{t}^{-\alpha} \quad\left(\text { expand by } N_{t} / N_{t}=1\right) \\
& =(1-\alpha) Y_{t} N_{t}^{-1}
\end{aligned}
$$

The formula in Appendix B (on page 109), was also mistakenly printed without symbols of the partial derivatives.

For the reader's convenience, the corrected formula appears below.

$$
\begin{aligned}
M C_{t} & =\frac{W_{t} / P_{t}}{\partial Y_{t} / \partial N_{t}} \\
& =\frac{W_{t} / P_{t}}{(1-\alpha) Y_{t} N_{t}^{-1}} \\
& =\frac{1}{1-\alpha} \frac{W_{t} / P_{t}}{Y_{t} / N_{t}}
\end{aligned}
$$

Rearranging:

$$
=\frac{1}{1-\alpha} \frac{W_{t} N_{t}}{Y_{t} P_{t}}
$$

*Corresponding author: Benjamin Schäfer, Chair of European Economic Policy, University Siegen, Unteres Schloß 3, 57072 Siegen, Germany, E-mail: economics@benjaminschaefer.de http://orcid.org/0000-0002-1696-3894 